J. Clin. Chem. Clin. Biochem.

Vol. 27, 1989, pp. 839-845

(C) 1989 Walter de Gruyter \& Co. Berlin $\cdot$ New York

\title{
1-Anilino-8-naphthalenesulphonate Binding Parameters in Red Cell Membranes Does Diabetes Mellitus Affect Cell Membrane Dynamics?
}

\author{
By C. Watala and Zofia Jóźwiak \\ Katedra Biofizyki, Uniwersytet Lódzki, Lódź, Poland
}

(Received December 23, 1988/June 8, 1989)

\begin{abstract}
Summary: In this study we report the use of 1-anilino-8-naphthalenesulphonate as a fluorescence probe to investigate the properties of plasma membranes derived from normal and diabetic red blood cells.

The binding of 1-anilino-8-naphthalenesulphonate to diabetes-affected erythrocyte membranes, as compared with controls, was measured by means of fluorescence polarization and fluorescence titration techniques.

These measurements demonstrated anomalous 1-anilino-8-naphthalenesulphonate binding to pathological red cell membranes. The amount of 1-anilino-8-naphthalenesulphonate bound to diabetic erythrocyte membranes was greater than that of controls. This fluorometric study indicated that the outer monolayer binding of 1-anilino-8-naphthalenesulphonate was markedly augmented in the erythrocyte membranes of diabetic patients. Significant correlations were found between 1-anilino-8-naphthalenesulphonate binding parameters and membrane lipid composition. The correlation between these binding parameters and non-enzymatic protein glycation was poor or moderate.
\end{abstract}

Though the fluorescence intensity and emission maximum were quite similar in both groups investigated, binding studies revealed that there were approximately 1.2 times the number of 1-anilino-8-naphthalenesulphonate binding sites and a $33 \%$ increase in the $K_{\mathrm{D}}$ value in diabetic membranes, suggesting significant differences in the environment of the 1-anilino-8-naphthalenesulphonate binding sites in these two groups of patients.

The results presented in this report indicate that

(a) 1-anilino-8-naphthalenesulphonate is a sensitive probe of membrane architecture alterations, and can be used to elucidate the perturbating effects of sterols in membrane systems, and

(b) that significant differences in membrane dynamics exist between normal and diabetic red cell membranes.

The possibility that the increase in bound dye in diabetics was caused by enhanced lateral compressibility, or density fluctuations, or whether it was due to additional binding sites at the boundary of heterogeneous lipid clusters is discussed.

\section{Introduction}

The revival of interest in fluorescence probes in recent years has resulted in numerous studies dealing with the pertinence of selected fluorophores for monitoring changes of membrane structure and dynamics $(1,2)$.
The technique of fluorescence spectroscopy has been used to probe many parameters of membrane structure using a variety of extrinsic probe molecules $(2$, 3 ), and several chemicals have been especially designed for this purpose. Amongst them, 1-anilino-8- 
naphthalenesulphonate is one of the most commonly used, its fluorescence being extremely sensitive to changes in the probe environment, as the probe binds non-covalently both to membrane proteins and lipids. Although certain aspects of 1-anilino-8-naphthalenesulphonate fluorescence remain to be evaluated, numerous physical parameters of 1-anilino-8-naphthalenesulphonate fluorescence have already been thoroughly explored. It was therefore possible to develop an adequate methodological approach to the reliable study of 1-anilino-8-naphthalenesulphonate fluorescence alterations (4). Showing negligible interference with membranes and possessing convenient adsorption characteristics, 1-anilino-8-naphthalenesulphonate remains the fluorescence probe of choice for numerous in vivo and in vitro experiments. It is known to bind to polar-apolar interfaces, with the chromophoric group extending into the hydrocarbon core and the sulphonate group located in the plane of the membrane polar head-groups. Membrane lipids and proteins are practically the only components of cell membrane structures possessing high affinity for 1-anilino-8-naphthalenesulphonate. Indeed, membrane proteins and membrane lipids are only two main types of 1-anilino-8-naphthalenesulphonate binding sites observed in biological membranes $(1,4)$.

Biological membranes are considered to be bidimensional quasifluids, which consist of amphipathic lipid molecules arranged in a bilayer and containing more sparsely distributed proteins. Membrane architecture is therefore considerably influenced by lateral and rotationel diffusion of the components. This diffusion, although subject to certain restrictions, is significantly influenced by the lipid composition of the membrane, specifically regulates membrane fluidity $(3,5)$.

Overwhelming evidence has accumulated confirming that membrane fluidity is involved in the control of an increasing number of physiological processes and that derangements of normal fluidity are involved in some pathological states.

Diabetes mellitus, which has been very widely investigated, is an example of metabolic disorder that may affect cell membrane structure, and disordered membrane fluidity has occasionally been reported in diabetic subjects $(6-10)$.

The aim of our study was to evaluate the alterations of membrane dynamic parameters of red blood cells in diabetic children compared with a control group. For this purpose, we used fluorescence polarization and fluorescence titration techniques to determine the 1-anilino-8-naphthalenesulphonate affinity and the number of 1-anilino-8-naphthalenesulphonate binding sites, as well as membrane anisotropy.

\section{Materials and Methods}

\section{Subjects}

Twenty-two type 1 diabetic subjects (12 boys and 10 girls), aged $8-17$ years at the end of the study on June 301987 , free from any accompanying diabetic complications, were compared with 25 healthy control subjects (11 boys and 14 girls) covering a comparable age range. All the diabetic patients attended the out-patient clinic of the Paediatric Clinic of Medical Academy of Łódź. Control subjects were selected from the patients hospitalized in the laryngology and surgery divisions of the same clinic. All the procedures were in keeping with the ethical standards of the hospital's Committee on Human Experimentation. All patients were free from haemolytic and other diseases. Following the introduction of tighter metabolic control, all the selected diabetics received two daily injections of intermediate- or long-acting insulin mixed in varied proportions. The following parameters were documented: sex, age, age at the onset of diabetes, duration of diabetes, fasting blood glucose [mmol/l], glycated haemoglobin [ $\mu \mathrm{mol}$ of 5-hydroxymethylfurfuraldehyde attached per $1 \mathrm{~g}$ of $\mathrm{Hb}$, height [cm], weight $[\mathrm{kg}]$ and daily insulin dose [IU/kg] (tab. 1).

Tab. 1. Clinical characteristics of investigated subjects and red blood cell protein glycation.

Number of subjects given in parentheses. Values of glycaemia represent the mean of individual averages of 7 fasting blood glucose assays. Each value represents mean $\pm 1 \mathrm{SD}$; ranges are given below the means; $p=1$ a, where a represents the level of significance. HMF = hydroxymethylfurfural

\begin{tabular}{|c|c|c|c|}
\hline Parameter & $\begin{array}{l}\text { Controls } \\
(25)\end{array}$ & $\begin{array}{l}\text { Diabetics } \\
(22)\end{array}$ & $\begin{array}{l}p=P \\
(T<t, n)\end{array}$ \\
\hline Age (years) & $\begin{array}{l}14.8 \pm 3.1 \\
(8-17)\end{array}$ & $\begin{array}{l}16.1 \pm 2.3 \\
(14-17)\end{array}$ & 0.944 \\
\hline $\begin{array}{l}\text { Diabetes duration } \\
\text { (years) }\end{array}$ & - & $\begin{array}{l}4.93 \pm 2.04 \\
(3-14)\end{array}$ & \\
\hline $\begin{array}{l}\text { Fasting glycaemia } \\
(\mathrm{mmol} / \mathrm{l})\end{array}$ & $\begin{array}{l}3.94 \pm 0.56 \\
(3.3-5.8)\end{array}$ & $\begin{array}{l}8.56 \pm 2.83 \\
(5.7-19.3)\end{array}$ & 1.000 \\
\hline $\begin{array}{l}\mathrm{HbA}_{1 \mathrm{c}}(\mu \mathrm{mol} \\
\mathrm{HMF} / \mathrm{g} \mathrm{Hb})\end{array}$ & $\begin{array}{l}4.0 \pm 1.0 \\
(2.9=5.4)\end{array}$ & $\begin{array}{l}6.4 \pm 1.5 \\
(5.0-10.8)\end{array}$ & 1.000 \\
\hline $\begin{array}{l}\text { Membrane protein } \\
\text { glycation (nmol } \\
\text { HMF/g protein) }\end{array}$ & $\begin{array}{l}22.1 \pm 1.9 \\
(16.9-24.2)\end{array}$ & $\begin{array}{l}26.1 \pm 4.1 \\
(23.7-31.8)\end{array}$ & 1.000 \\
\hline $\begin{array}{l}\text { Insulin dose } \\
\text { (IU/kg) }\end{array}$ & - & $\begin{array}{l}1.04 \pm 0.41 \\
(0.42-1.92)\end{array}$ & \\
\hline $\begin{array}{l}\text { Body mass index } \\
\left(\mathrm{cm} / \mathrm{kg}^{2}\right)\end{array}$ & $\begin{array}{l}18.82 \pm 3.74 \\
(12.1-21.9)\end{array}$ & $\begin{array}{l}19.94 \pm 4.79 \\
(12.1-30.90\end{array}$ & 0.808 \\
\hline
\end{tabular}

\section{Chemical procedures}

Fasting blood glucose was measured by an automatic hexokinase method (Boehringer-Mannheim, FRG). 'Glycation of membrane proteins and haemoglobin was assayed as described in detail in our previous papers $(8,10)$ using the method adapted from 1.c. (11). For each sample a blank was run, in which the ketoamine derivative of the glycated protein was reduced by sodium borohydride (SIGMA) to the form not giving colour formation by thiobarbituric acid (12). A standard curve was prepared using 5-hydroxymethylfurfuraldehyde (SIGMA). Cholesterol and phospholipids of erythrocyte ghost membranes, prepared according to Marchesi \& Palade (13), were assayed by the methods of Babson et al. (14) and Vaskovsky et al. (15) after extraction according to l.c. (16): 


\section{Fluorescence measurements}

A reproducible fluorescence polarization technique was employed to monitor membrane fluidity.

Magnesium 1-anilino-8-naphthalenesulphonate (purchased from SERVA) $5 \mathrm{mmol} / 1$ in Tris- $\mathrm{HCl}$ buffer $(0.05 \mathrm{~mol} / \mathrm{l}, \mathrm{pH} 7.0)$ was added to a dispersion of erythrocyte ghosts $(100 \mathrm{mg} / 1$ protein) to a final 1-anilino-8-naphthalenesulphonate concentration of $25 \mu \mathrm{mol} / 1$.

1-Anilino-8-naphthalenesulphonate fluorescence was excited using the $366 \mathrm{~nm}$ mercury line selected with the excitation monochromator (4 $\mathrm{nm}$ slit). Emission was observed at $480 \mathrm{~nm}$ through an interference filter, with a $7.5 \mathrm{~nm}$ half band pass, and an additional $1 \mathrm{~cm}$ of aqueous $2 \mathrm{~mol} / 1 \mathrm{NaNO}_{2}$ as an ultraviolet cutoff filter. We employed $10 \mathrm{~mm} \times 10 \mathrm{~mm} \times 40 \mathrm{~mm}$ quartz Pye Unicam cuvettes.

Double reciprocal plots of the binding of 1-anilino-8-naphthalenesulphonate to membranes were used to determine the average apparent dissociation constant, $K_{\mathrm{D}}$, and the number of 1-anilino-8-naphthalenesulphonate binding sites, $n$. Lines were fitted by linear regression analysis. In the first case, $5 \mu$ l aliquots of $0.5 \mathrm{mmol} / 1$-anilino-8-naphthalenesulphonate solution in Tris-HCl buffer $(0.05 \mathrm{~mol} / 1, \mathrm{pH} 7.0)$ were added directly to $50 \mathrm{mg}$ protein per litre ghost dispersion sample in the culvette, using a Gilmont burette, and with constant stirring of the sample. The average apparent dissociation constant, $K_{\mathrm{D}}$, was estimated as follows:

$1 / \mathrm{I}=1 / \mathrm{I}_{\max }+\left\{K_{\mathrm{D}} /\left[\mathrm{I}_{\max } *(\mathrm{ANS})\right]\right\}$

where $I$ and $I_{\max }$ represent the observed fluorescence intensity and the maximal fluorescence intensity at the excess of 1-anilino-8-naphthalenesulphonate added, respectively (17). The number of 1-anilino-8-naphthalenesulphonate (ANS) binding sites, $n$, defined as the amount of 1-anilino-8-naphthalenesulphonate bound to $1 \mathrm{mg}$ of membrane protein, was calculated in accordance with the equation:

$(\mathrm{ANS}) / \mathrm{I}=1 / \mathrm{q}+\left[K_{\mathrm{D}} /\left(\mathrm{q} * \mathbf{n} * c_{\mathrm{P}}\right)\right]$

where $\mathrm{q}$ is a constant depending on the value of quantum yield of 1-anilino-8-naphthalenesulphonate fluorescence, and $c_{\mathrm{p}}$ is the membrane protein concentration, expressed in $\mathrm{g} / \mathrm{l}$ (17). In order to determine the number of 1-anilino-8-naphthalenesulphonate binding sites, $1.5 \mathrm{mmol} / \mathrm{l}$ Tris buffer 1-anilino-8-naphthalenesulphonate solution was titrated with a ghost dispersion (protein $350 \mathrm{mg} / \mathrm{l}$ ), by adding $20 \mu \mathrm{l}$ aliquots of membrane suspensions, up to the final membrane protein concentration of $30-35 \mathrm{mg} / \mathrm{l}$. The plot was linear for the protein concentration of above $10 \mathrm{mg} / \mathrm{l}$. To avoid the effect of fluorescence adsorption by 1-anilino-8-naphthalenesulphonate added, the observed value of emitted fluorescence light was corrected as follows:

$\mathrm{I}_{\text {corr }}=\left\{\mathrm{I}_{\mathrm{obs}} *[2.303 * \mathrm{~A} *(\mathrm{ANS})]\right\} /\left\{1-10^{[(\mathrm{ANS}) *(-\mathrm{A})]}\right\} \quad(\mathrm{Eq} .3)$,

where $\mathrm{I}_{\text {corr }}$ and $\mathrm{I}_{\text {obs }}$ represent respectively corrected and observed values of 1-anilino-8-naphthalenesulphonate fluorescence, (ANS) is the probe concentration in the sample, and A is the molecular absorption coefficient at $366 \mathrm{~nm}$; empirically estimated to be equal to $51401 \cdot \mathrm{mol}^{-1} \cdot \mathrm{cm}^{-1}$ (molar lineic absorbance $\varepsilon_{366 \mathrm{~nm}}=514 \mathrm{~m}^{2} / \mathrm{mol}$ ). The above contribution is significant at concentrations of 1-anilino-8-naphthalenesulphonate above $1 \mu \mathrm{mol} / 1$ (18).

The polarization of fluorescence reflects the mobility of the fluorescent molecules and the transfer of excitation energy between them. In the case of rigidly arranged, randomly oriented molecules, the value of the degree of polarization for linearly polarized excitation light depends only on the angle between the absorption and emission oscillators. As the extent of depolarization depends on the extent of the rotation, reflecting the mobility of the molecules surrounding 1-anilino-8-naphthalenesulphonate, the fluorescence polarization technique can be used to determine the microviscosity of biological membranes (4).

The excitation light was vertically polarized and the emission intensity was subsequently measured first through a GlanThomson vertical polarizer, and then through a horizontal one.

Steady-state fluorescence emission anisotropies were calculated according to the equation:

$\mathrm{r}=\left(\mathrm{I}_{\mathrm{Vv}}-\mathrm{I}_{\mathrm{VH}} * \mathrm{G}\right) /\left(\mathrm{I}_{\mathrm{Vv}}+2 \mathrm{I}_{\mathrm{VH}} * \mathrm{G}\right)$

where $I_{\mathrm{vv}}$ and $I_{\mathrm{VH}}$ represent respectively the vertical (parallel) and horizontal (perpendicular) orientation of the electric vector of emission at the vertical excitation, and $G=I_{H V} / I_{H H}$ is the grating transmission factor (2).

All the fluorescence measurements were conducted in the Department of Animal Biochemistry, Institute of Molecular Biology (Jagiellonian University, Cracow) thanks to the courtesy of Doc. dr. Z. Wasylewski.

\section{Statistical analysis}

Each determination was performed in triplicate, and the results are expressed as the mean of individual means for all the examined systems. The significance of differences were tested by Student's t test, and normal distribution variables were checked by $\chi^{2}$ compatibility testing. Partial correlation analysis was employed to establish the relationships between the examined parameters.

\section{Results}

Fluorescence anisotropy values, as a measure of erythrocyte membrane rigidization, are elevated in diabetic subjects when compared with controls, indicating lowered membrane fluidity in diabetes (tab. 2). Related changes were found in the membrane cholesterol content, membrane cholesterol:phospholipid ratio and membrane cholesterol:phosphatidylcholine ratio

Tab. 2. 1-Anilino-8-naphthalenesulphonate binding parameters and 1-anilino-8-naphthalenesulphonate anisotropy in erythrocyte membranes in control and diabetic juveniles.

Each value represents mean $\pm 1 \mathrm{SD}$. Number of subjects given in parentheses.

$K_{\mathrm{D}}$ is the average apparent dissociation constant for the 1-anilino-8-naphthalenesulphonate-membrane complex; $n$, number of 1-anilino-8-naphthalenesulphonate binding sites per $1 \mathrm{mg}$ of membrane protein; $\mathrm{r}_{\text {ANS, }}$ 1-anilino-8-naphthalenesulphonate anisotropy; $p=1-a$, where a represents the level of significance. 1-Anilino-8-naphthalenesulphonate fluorescence was excited at $366 \mathrm{~nm}$, emission being recorded at $480 \mathrm{~nm}$; temperature $25^{\circ} \mathrm{C}$.

\begin{tabular}{llll}
\hline Parameter & $\begin{array}{l}\text { Controls } \\
(25)\end{array}$ & $\begin{array}{l}\text { Diabetics } \\
(22)\end{array}$ & $\begin{array}{l}\mathrm{p}=\mathrm{P} \\
(\mathrm{T}<\mathrm{t}, \mathrm{n})\end{array}$ \\
\hline$K_{\mathrm{D}}[\mathrm{l} / \mathrm{mol}]$ & $0.022 \pm 0.003$ & $0.030 \pm 0.009$ & 1.000 \\
$\mathrm{n}\left[\mathrm{mg}^{-1}\right]$ & $0.315 \pm 0.072$ & $0.374 \pm 0.097$ & 0.980 \\
$\mathrm{r}_{\text {ANs }}$ & $0.228 \pm 0.025$ & $0.241 \pm 0.022$ & 0.976 \\
\hline
\end{tabular}


(tab. 3). However, the anisotropic alterations were moderately significant $(p=0.976)$, in contrast to the high significance of the fluctuations in cholesterol content. Non-enzymatic glycation of both membrane proteins and haemoglobin was also found to be elevated in diabetes, the changes being significant in each case (tab. 4). The 1-anilino-8-naphthalenesulphonate binding parameters and 1-anilino-8-naphthalenesulphonate anisotropy coefficient correlated most strongly with the membrane cholesterol content and cholesterol: phospholipid molar ratio. There was no significant correlation between 1-anilino-8-naphthalenesulphonate binding parameters or 1-anilino8-naphthalenesulphonate anisotropy and the extent of non-enzymatic glycation of either membrane proteins or haemoglobin (tab. 4).

Tab. 3. Lipid composition of erythrocyte membranes in control and diabetic juveniles.

Each value represents mean \pm 1 SD. Number of subjects given in parentheses.

$p=1-a$, where a represents the level of significance.

\begin{tabular}{llll}
\hline Parameter & $\begin{array}{l}\text { Controls } \\
(25)\end{array}$ & $\begin{array}{l}\text { Diabetics } \\
(22)\end{array}$ & $\begin{array}{l}\mathrm{p}=\mathrm{P} \\
(\mathrm{T}<\mathrm{t}, \mathrm{n})\end{array}$ \\
\hline $\begin{array}{l}\text { Cholesterol } \\
\text { (mmol/g protein) }\end{array}$ & $0.48 \pm 0.09$ & $0.59 \pm 0.04$ & 1.000 \\
$\begin{array}{l}\text { Cholesterol } \\
\frac{\mathrm{P}}{\text { Phosphatidylcholine }}\end{array}$ & $2.33 \pm 0.46$ & $3.11 \pm 0.37$ & 1.000 \\
$\frac{\text { Cholesterol }}{\text { Phospholipids }}$ & $0.68 \pm 0.07$ & $0.84 \pm 0.07$ & 1.000 \\
$\begin{array}{l}\text { Phosphatidylcholine } \\
\text { Sphingomyelin }\end{array}$ & $0.88 \pm 0.13$ & $0.93 \pm 0.16$ & 0.858 \\
\hline
\end{tabular}

Figures 1 and 2 present examples of plots derived from Eq. 1 and 2 respectively, for control and for diabetic children.

The results from each sample of prepared erythrocyte membrane ghosts wère recorded graphically, in order to calculate the values $K_{\mathrm{D}}$ and $\mathrm{n}$ for every subject examined. Table 2 shows the medn values of average apparent dissociation constants and numbers of 1-anilino-8-naphthalenesulphōnate binding sites for normal and diabetic children.

The recorded differences confirm that the membrane dynamics is altered in diabetes. Very significant differences in $K_{\mathrm{D}}$ values testify to reduced 1-anilino-8naphthalenesulphonate affinity to diabetic erythrocyte membranes. Recorded differences in the number of 1-anilino-8-naphthalenesulphonate binding sites are less significant, but they indicate that the diabetic erythrocyte membrane has an increased capacity for the probe molecules.

\section{Discussion}

The interaction of 1-anilino-8-naphthalenesulphonate with erythrocyte membranes of diabetic children suggests the existence of significant alterations in membrane structure compared with normal erythrocytes.

Since the number of bound 1-anilino-8-naphthalenesulphonate molecules only increases with increasing 1-anilino-8-naphthalenesulphonate concentration up to a certain saturation limit, specific binding sites are assumed to exist in membranes. In membranes com-

Tab. 4. Partial correlation coefficients between examined parameters in control and diabetic subjects.

ANS, 1-anilino-8-naphthalenesulphonate; $K_{\mathrm{D}}$, dissociation constant of 1-anilino-8-naphthalenesulphonate-membrane complex; $n$, number of binding sites; $r_{A N S}, 1$-anilino-8-naphthalenesulphonate anisotropy. Critical values: $\mathrm{p}(0.95)=0.47, \mathrm{p}(0.99)=0.53$.

\begin{tabular}{|c|c|c|c|c|c|c|c|c|c|}
\hline & & 1 & 2 & 3 & 4 & 5 & 6 & 7 & 8 \\
\hline 1 & $\mathbf{r}_{\text {ANS }}$ & & & & & & & & \\
\hline 2 & $K_{\mathrm{D}}$ & 0.624 & & & & & & & \\
\hline 3 & $\mathbf{n}$ & 0.581 & 0.396 & & & & & & \\
\hline 4 & Cholesterol & 0.856 & 0.470 & 0.599 & & & & & \\
\hline 5 & $\frac{\text { Cholesterol }}{\text { Phospholipids }}$ & 0.702 & 0.492 & 0.604 & 0.899 & & & & \\
\hline 6 & $\frac{\text { Cholesterol }}{\text { Phosphatidylcholine }}$ & 0.649 & 0.271 & 0.627 & 0.742 & 0.861 & & & \\
\hline 7 & $\frac{\text { Phosphatidylcholine }}{\text { Sphingomyelin }}$ & -0.015 & 0.102 & 0.191 & 0.140 & -0.036 & -0.312 & & \\
\hline 8 & Membrane protein glycation & 0.312 & 0.155 & 0.024 & 0.242 & 0.184 & 0.167 & $" 0.130$ & \\
\hline \multirow[t]{2}{*}{9} & $\mathrm{HbA}_{1 c}$ & 0.054 & 0.209 & 0.311 & 0.301 & 0.075 & 0.047 & -0.048 & 0.217 \\
\hline & & 1 & 2 & 3 & 4 & 5 & 6 & 7 & 8 \\
\hline
\end{tabular}



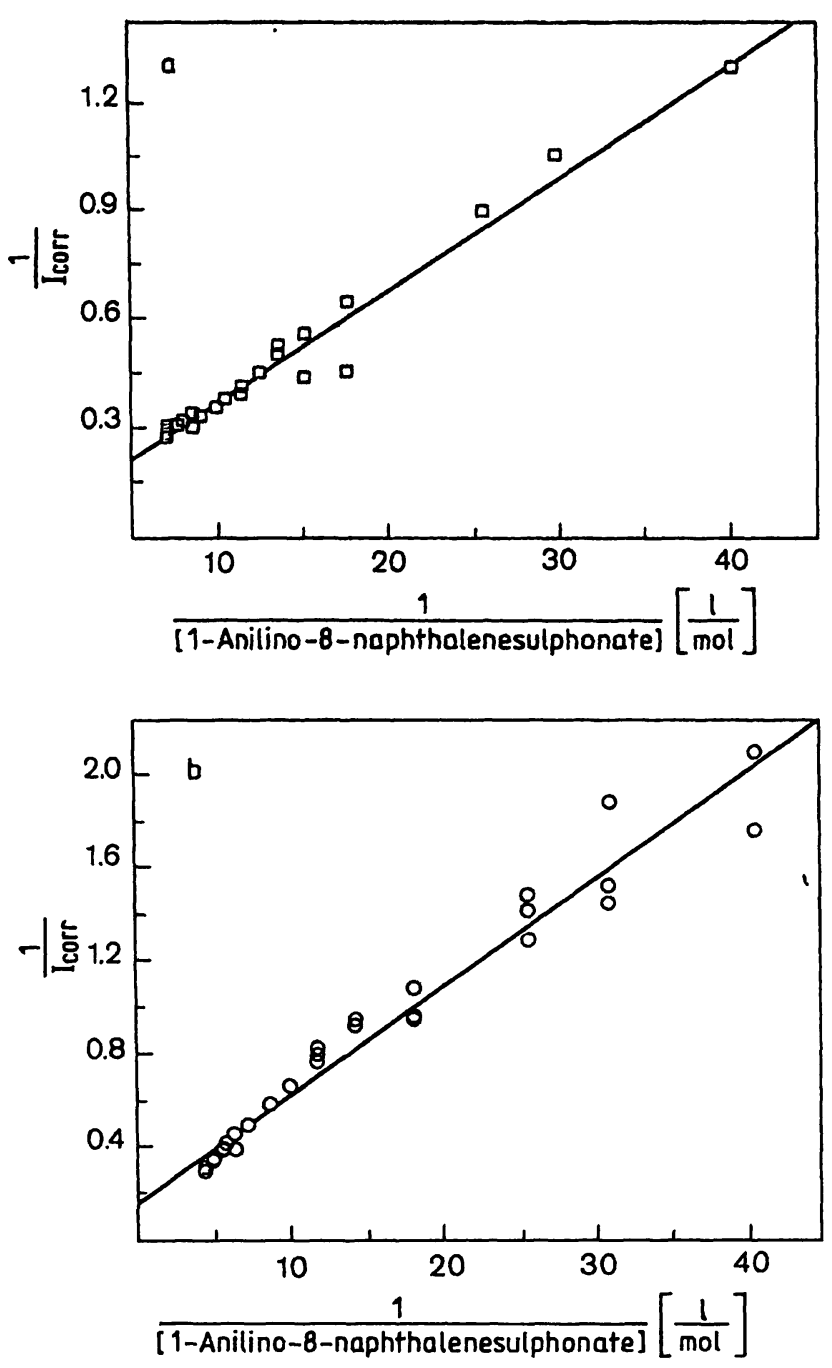

Fig. 1. Estimation of average apparent dissociation constants $K_{\mathrm{D}}$ of 1-anilino-8-naphthalenesulphonate-membrane complex.

Examples of plots of fluorescence titration of control (a) and diabetic (b) erythrocyte ghost dispersion by 1anilino-8-naphthalenesulphonate. $\mathrm{I}_{\text {corr }}$, corrected value of fluorescence intensity. The initial concentration of membrane protein: $50 \mathrm{mg} / \mathrm{l}$; temperature $25^{\circ} \mathrm{C}$.

posed of a mixture of different lipids, most 1-anilino8-naphthalenesulphonate molecules are bound in lecithin-sphingomyelin pockets, or to a much lesser extent in the shallow binding sites associated with the presence of cholesterol, although cholesterol alone does not bind 1-anilino-8-naphthalenesulphonate at all. Since lecithin and sphingomyelin heads bind 1-anilino-8-naphthalenesulphonate most avidly, the first mentioned type of binding will essentially predominate $(4,19)$. An increased cholesterol: lecithin molar ratio leads to the other, quite different type of 1-anilino-8-naphthalenesulphonate binding, where 1-anilino-8-naphthalenesulphonate molecules are located in cholesterol-lecithin pockets, which are much more exposed to extrinsic water. This environment should result in a considerable quenching of 1-anilino-
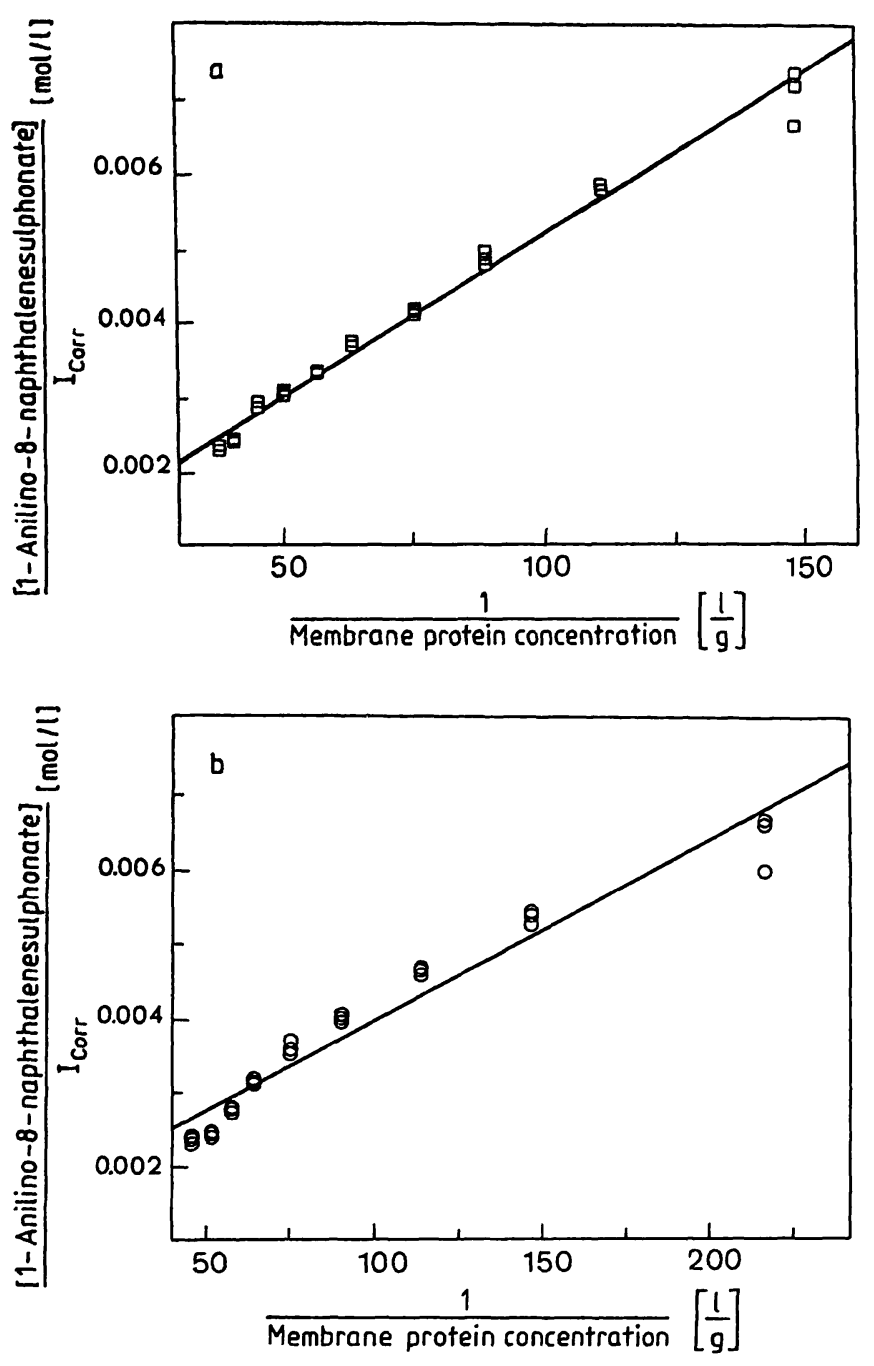

Fig. 2. Estimation of the number of 1-anilino-8-naphthalenesulphonate binding sites in control (a) and diabetic (b) erythrocyte ghosts.

An example of a plot of the fluorescence titration of $1.5 \mathrm{mmol} / 1$ 1-anilino-8-naphthalenesulphonate solution by a membrane dispersion, protein concentration 350 $\mathrm{mg} / \mathrm{l}$. $\mathrm{I}_{\text {corr }}$, corrected value of fluorescence intensity. Temperature $25^{\circ} \mathrm{C}$.

8-naphthalenesulphonate fluorescence and a decreased fluorescence yield, which in fact is found to be the case. Indeed, 1-anilino-8-naphthalenesulphonate anisotropy is correlated significantly with the membrane cholesterol content and the membrane cholesterol: phospholipid ratio (tab. 4). Although the elevated level of membrane protein glycation could also considerably affect membrane fluidity, the calculated correlation coefficients, relating both 1-anilino-8-naphthalenesulphonate anisotropy and 1-anilino-8-naphthalenesulphonate binding parameters to membrane protein or haemoglobin glycation, are obviously low. Hence, it seems reasonable to conclude that the effect of membrane protein glycation on membrane lipid fluidity is negligible. The number of protein binding sites for 1-anilino-8-naphthalene- 
sulphonate in biological membranes is considerably lower than the number of lipid binding sites, whereas their affinity is greater (the ratio of 1-anilino-8-naphthalenesulphonate protcin $_{1}$ 1-anilino-8-naphthalenesulphonate $_{\text {lipid }}$ equals to $1: 10$ to $\left.1: 100\right)$ (4). Thus, as the concentration of 1-anilino-8-naphthalenesulphonate is increased from a low value, the probe binds first to the proteins and subsequently to lipids. At 1-anilino-8-naphthalenesulphonate concentrations commonly used, most of the protein binding sites are already occupied by 1-anilino-8-naphthalenesulphonate and the fluorescence of lipid-bound 1-anilino-8naphthalenesulphonate gradually predominates in the total fluorescence because of the higher number of lipid 1-anilino-8-naphthalenesulphonate-binding sites. Thus, the effect of glycation on 1-anilino-8naphthalenesulphonate binding to membrane proteins, even if it is pronounced, could be imperceptible or remained unrecorded, being screened by fluorescence from the population of lipid-bound 1-anilino8-naphthalenesulphonate molecules.

Accumulated evidence confirms the dominance of fluorescence from 1-anilino-8-naphthalenesulphonate bound to lecithin-sphingomyelin pockets in natural membranes $(19,20,21)$.

According to Tsong (22), the adsorption of 1-anilino8-naphthalenesulphonate molecules to the phospholipid heads is quickly followed by their submersion to deeper binding sites. Hence, at relatively high 1-anilino-8-naphthalenesulphonate concentrations, when most of the deeper binding sites are already occupied, some 1-anilino-8-naphthalenesulphonate molecules have to remain bound to surface binding sites. As the 1-anilino-8-naphthalenesulphonate fluorescence from surface binding sites is attributed to a shorter lifetime and a lower degree of polarization, these may account for the decreased average lifetime and lower value of fluorescence polarization in normal erythrocyte membranes, compared with diabetic ones. The possible effect of membrane glycation on 1-anilino-8-naphthalenesulphonate binding parameters and 1-anilino-8-naphthalenesulphonate averaged anisotropy coefficient is evidently minute (tab. 4), when compared with that reported for 1,6-diphenylhexatriene-1,3,5-labelled erythrocyte membrane

\section{References}

1. Radda, G. K. (1975) Fluorescent probes. In: Methods in Membrane Biology (Korn, E. D., ed.) Plenum Press, New York 4, 97-188.

2. Shinitzky, M. \& Barenholz, Y. (1978) Fluidity parameters of lipid regions determined by fluorescence polarization. Biochim. Biophys. Acta 515, 367-394. ghosts $(r=0.504)(9)$, and it permits certain conclusions concerning the depth-dependent lipid bilayer alterations induced by the glycation process.

The appearance of additional or even a new class of 1-anilino-8-naphthalenesulphonate binding sites may be due to cholesterol-induced conformational changes resulting in the deshielding of previously inaccessible sites (23). The significant correlation between the number of 1-anilino-8-naphthalenesulphonate binding sites and the membrane cholesterol: lecithin ratio seems to confirm the above hypothesis (tab. 4).

In lipid fluid states, which in most cases are physiologically relevant, cholesterol molecules act as rigidizers, by perturbing the ordered membrane structure. It elevates the temperature of lipid phase transition, thereby broadening the temperature range of transition $(2,3,23)$.

The binding of amphipathic molecules of 1-anilino8-naphthalenesulphonate to lipid bilayers is assumed to involve insertion of the apolar naphthalene moiety into the hydrocarbon region, while the charged sulphonate moiety remains in the plane of the polar head groups $(20,21,24)$. Thus, any enhanced lateral compressibility in the liquid crystalline state near the temperature of lipid phase transition $\left(t_{m}\right)$ could result in increased dye binding in this region, by allowing the insertion of 1-anilino-8-naphthalenesulphonate into its membrane binding site with minimal perturbation (25).

Penetration of foreign molecules into lipid bilayers also seems to be increased near a phase transition point, as high lateral compressibility of the monolayer is associated with the onset of a gel-like transition. In turn, large density fluctuations and enhanced compressibility probably occur in the vicinity of a phase transition point, so dye binding should be altered in any disturbed lipid region $(26-28)$.

\section{Acknowledgement}

We express our sincere indebtedness to $\mathrm{Dr}$. $O$. Wenhrynowicz (Medical Academy of Cracow) for his generous, brief discussion of the results and for his invaluable advice concerning the methodology. The study was supported by the Grant R.P.II.11.4.7.
3. Shinitzky, M. \& Henkart, P. (1980) Fluidity and cell membranes: current concepts and trends. International Rev. Cytology 60, 121-138.

4. Slavik, J. (1982) Anilinonaphthalenesulfonate as a probe of membrane composition and function. Biochim. Biophys. Acta 694, 1-25. 
5. Shinitzky, M. (1984) Membrane fluidity and cellular functions. In: Physiology of Membrane Fluidity (Shinitzky, M., ed.) Plenum Press, New York 1, 1-51.

6. Baba, Y., Kai, M., Kamada, T., Setoyama, S. \& Otsuji, S. (1978) Higher levels of erythrocyte membrane microviscosity in diabetes. Diabetes 28, 1138-1139.

7. Bryszewska, M., Watała, C. \& Torzccka, W. (1986) Changes in fluidity and composition of membranes and in composition of plasma lipids in type 1 diabetes. British $\mathrm{J}$. Haematol. 62, 111-116.

8. Watała, C. \& Kordacka, M. (1987) Nonenzymatic glycosylation of proteins. II. Does glycosylation of low density lipoproteins affect lipid composition of erythrocyte membranes? Ann. Clin. Res. 19, 194-197.

9. Watała, C., Kordacka, M., Loba, A., Jóźwiak, Z. \& Nowak, S. (1987) Analysis of membrane fluidity alterations and lipid disorders in type 1 diabetic children and adolescents. Acta Diabetol. Lat. 24, $141-148$.

10. Watała, C., Zawodniak, M., Bryszewska, M. \& Nowak, S. (1986) Nonenzymatic protein glycosylation. I. Lowered erythrocyte membrane fluidity in juvenile diabetics. Ann. Clin. Res. 17, 327-332.

11. Flückiger, R. \& Winterhalter, K. H. (1976) In vitro synthesis of hemoglobin A1c. FEBS Lett. 71, 356-360.

12. Kennedy, L. \& Elder, E. (1983) Rapid, accurate colorimetric assay of non-enzymatically glycosylated serum proteins. Diabetologia 24, 70-71.

13. Marchesi, V. T. \& Palade, G. E. (1967) The localization of $\mathrm{Mg}-\mathrm{Na}-\mathrm{K}$-activated adenosine triphosphatase in red cell ghost membranes. J. Cell Biol. 35, 385-403.

14. Babson, A. L., Shapiro, P. O. \& Philips, G. E. (1962) A new assay for cholesterol and cholesterol esters in serum which is not affected by bilirubin. Clin. Chim. Acta 7, 800-809.

15. Vaskovsky, V. E., Kostetsky, E. Y. \& Vasendin, L. M. (1975) A universal reagent for phospholipid analysis. J. Chromatogr. 114, 129-141.

16. Rose, H. G. \& Oklander, M. (1965) Improved procedure for the extraction of lipids from human erythrocytes. J. Lipid Res. 6, 128-131.
17. Wang, J. L. \& Edelman, G. M. (1971) Fluorescent probes for conformational states of proteins. IV. The pepsinogenpepsin conversion. J. Biol. Chem. 246, 1185-1191.

18. McClure, W. O. \& Edelman, G. M. (1967) Fluorescent probes for conformational states of proteins. II. The binding of 2-p-toluidinylnaphthalene-6-sulfonate to $\alpha$-chymotrypsin. Biochemistry $6,559-566$.

19. Haynes, D. H. \& Steark, H. (1974) 1-Anilino-8-naphthalenesulphonate: a fluorescent probe of membrane surface structure, composition and mobility. J. Memb. Biol. 17, $313-340$.

20. Lesslauer, W., Cain, J. \& Blasie, J. K. (1971) On the location of 1-anilino-8-naphthalenesulphonate in lipid model systems. An X-ray diffraction study. Biochim. Biophys. Acta 241, 547-566.

21. Lesslauer, W., Cain, J. \& Blasie, J. K. (1972) X-ray diffraction studies of lecithin bimolecular leaflets with incorporated fluorescent probes. Proc. Natl. Acad. Sci. U. S. A. 69, 1499-1503.

22. Tsong, T. Y. (1975) Effect of a phase transition on the kinetics of dye transport in phospholipid bilayer structures. Biochemistry 14, 5409-5414.

23. Papahadjopoulos, D., Jacobson, K., Nir, S. \& Isac, T (1973) Phase transitions in phospholipid vesicles. Fluorescence polarization and permeability measurements concerning the effect of temperature and cholesterol. Biochim. Biophys. Acta 311, 330-348.

24. Colley, C. \& Metcalfe, J. (1972) The localization of small molecules in lipid bilayer. FEBS Lett. 24, $241-246$.

25. Lee, A. B., Birdsall, N. J. M., Metcalfe, J. C., Toon, P. A. \& Warren, G. B. (1974) Clusters in lipid bilayers and the interpretation of thermal effects in biological membranes. Biochemistry 13, 3699-3705.

26. Jacobson, K. \& Papahadjopoulos, D. (1976) Effect of a phase transition on the binding of 1-anilino-8-naphthalenesulphonate to phospholipid membranes. Biophys. J. 16, $549-560$.

27. Jacobson, K. \& Wobschall, D. (1974) Rotation of fluorescent probes localized within lipid bilayer membranes. Chem. Phys. Lipids 12, 117-131.

28. Wu, S. \& McConnell, H. M: (1975) Phase separation in phospholipid membranes. Biochemistry 14, 847-854.

\section{Cezary Watała}

Chair of Biophysics

University of $€$ ódź

ul. Banacha 12/16

PL-90-237 Łódź 
